\title{
Adipose thyrotrophin receptor expression is elevated in Graves' and thyroid eye diseases ex vivo and indicates adipogenesis in progress in vivo
}

\author{
K J Starkey ${ }^{1}$, A Janezic ${ }^{2}$, G Jones ${ }^{2}$, N Jordan ${ }^{1,3}$, G Baker $^{1,4}$ and M Ludgate ${ }^{1}$ \\ ${ }^{1}$ Department of Medicine, University of Wales College of Medicine, Heath Park, Cardiff CF14 4XN, UK \\ ${ }^{2}$ Department of Surgery, University of Wales College of Medicine, Heath Park, Cardiff CF14 4XN, UK \\ ${ }^{3}$ Department of Medical Biochemistry, University of Wales College of Medicine and Cardiff and Vale NHS Trust, Heath Park, Cardiff CF14 4XN, UK \\ ${ }^{4}$ Department of Ophthalmology, University of Wales College of Medicine, Heath Park, Cardiff CF14 4XN, UK
}

(Requests for offprints should be addressed to M Ludgate; Email: ludgate@cf.ac.uk)

\begin{abstract}
The thyrotrophin receptor (TSHR) provides an autoantigenic link between the thyroid and orbit in Graves' (GD) and thyroid eye diseases (TED). We measured TSHR transcripts in different fat depots to determine whether TSHR expression levels are influenced by the autoimmune/inflammatory process and/or thyroid hormone status, using quantitative real-time PCR. Nine intact or fractionated adipose samples, from patients with GD and/or TED, were analysed ex vivo. Eight expressed the TSHR, at levels approaching the thyroid, and one was at the limit of detection. Thirteen/fifteen orbital and abdominal fat samples from patients free of GD and TED, measured ex vivo, were negative for TSHR transcripts and two were at the limit of detection. All preadipocyte samples induced to differentiate in vitro expressed the TSHR. To investigate the influence of thyroid hormone status on adipose TSHR expression, we induced hyper- and hypothyroidism in BALBc mice by administering tri-iodothyronine and propylthiouracil respectively. In euthyroid animals, whole fat samples were at the limit of detection and were not altered by thyroid hormone status. The results show that adipose TSHR expression ex vivo indicates adipogenesis in progress in vivo and is associated with the autoimmune/inflammatory process in GD and TED but is not restricted to the orbit or influenced by thyroid hormone status.
\end{abstract}

Journal of Molecular Endocrinology (2003) 30, 369-380

\section{Introduction}

Thyroid eye disease (TED) is a frequent complication of Graves' disease (GD). The orbital tissues in TED and the thyroids in GD display lymphocytic infiltration, indicating the autoimmune etiology of these disorders (Ludgate \& Baker 2002). In GD, the thyrotrophin receptor (TSHR) is the autoantigenic target of thyroid-stimulating antibodies (TSAB) which mimic the action of thyrotrophin (TSH) and cause hyperthyroidism and goitre (Paschke \& Ludgate 1997). The pathogenesis of TED is more complex and a variety of mechanisms contribute to the increase in orbital contents leading to proptosis, which accounts for most of the signs and symptoms (Heufelder et al. 2000). The extra-ocular muscles (EOM) can be enlarged in TED, primarily due to oedema, but the myocytes themselves are relatively unaffected (Hufnagel et al. 1987). Two further processes increase the contents of the orbit, production of glycosaminoglycans by orbital fibroblasts (Hansen et al. 1997) and hypertrophy and hyperplasia of the adipose tissue (Sorisky et al. 1996). The increase in fat cell number is the consequence of adipogenesis, in which preadipocytes differentiate into mature adipocytes. The process involves several distinct phases including growth arrest and the induction of the central transcriptional regulators of adipogenesis (Rosen \& Spiegelman 2000), peroxisome proliferator-activated receptor- $\gamma(\operatorname{PPAR} \gamma)$ and CCAAT/enhancer binding-protein- $\alpha(\mathrm{C} / \mathrm{EBP} \alpha)$.

The adipose tissue has also received considerable attention as the source of a putative autoantigenic 
link between the thyroid and the orbit, the TSHR. The majority of fat depots in rats (Endo et al. 1995) and guinea pigs (Roselli-Rehfuss et al. 1992) are considered to express a functional TSHR, as demonstrated by RT-PGR, TSH binding and TSH-induced cAMP accumulation (Haraguchi et al. 1996a). In addition, in vitro models revealed that TSHR expression was highest in rat preadipocytes undergoing adipogenesis to mature adipocytes (Haraguchi et al. 1996b).

TSHR expression in human fat is more controversial. In neonatal adipose tissue, TSH and TSAB mediate lipolysis in vitro (Marcus et al. 1988), indicating a functional TSHR on mature adipocytes. This in vitro effect declines with age, as does serum TSH which eventually attains adult levels following the TSH surge at birth.

In adult fat, the complete spectrum for TSH-binding sites, from absent to low and high affinity, has been reported (Mullin et al. 1976, Davies et al. 1978, Perros \& Kendall-Taylor 1994). TSHR transcripts in orbital fat were first inferred from RT-PCR studies of orbital contents which yielded a product, whereas the individual components, connective tissue and EOM did not and orbital fat was not tested (Feliciello et al. 1993). We demonstrated TSHR transcripts in TED orbital fat, using Northern blot analysis in which transcripts in normal orbital and abdominal fat were at the limit of detection (Crisp et al. 1997). Subsequently, this has been confirmed by RT-PCR and liquid hybridization analysis, the latter also indicating that, in common with rodent fat, TSHR expression in man is highest during adipogenesis (Valyasevi et al. 1999).

TSHR protein, detected by immunocytochemistry, has been reported by ourselves (Crisp et al. 2000) and others, on TED orbital fat tissues ex vivo and at all stages of the preadipocyte to mature adipocyte differentiation pathway in vitro (Bahn et al. 1998). Furthermore, although preadipocytes are unresponsive to TSH, $10 \mathrm{mU} / \mathrm{ml}$ of the hormone stimulates cAMP production in differentiating cells and mature adipocytes, irrespective of the depot (Crisp et al. 2000).

The situation in TED has become more complex since TSHR expression is clearly not restricted to the orbit, even though the receptor is most abundant in TED orbits (Crisp et al. 1997). At least two explanations could account for this: (1) a further autoantigen, with restricted orbital- or disease-associated expression, remains to be identified and (2) the extra-thyroidal changes are more systemic than previously appreciated. There is evidence from another extra-thyroidal manifestation, pretibial myxoedema $(\mathrm{PM})$ to support both points of view. Immunoglobulins from GD patients stimulate the production of intercellular adhesion molecule-1 from GD but not normal fibroblasts, highlighting a difference in these two populations of cells (Heufelder \& Bahn 1992) and TSHR immunoreactivity has been demonstrated in PM and normal skin biopsies (Rapoport et al. 2000, Daumerie et al. 2002).

Further support for the role of the TSHR in TED derives from the success in modelling the disease using TSHR primed $\mathrm{T}$ cells or genetic immunization (Many et al. 1999, Costagliola et al. 2000).

The aim of the present study was to investigate whether TSHR transcript levels vary in fat from different depots and/or is influenced by the autoimmune process in GD or thyroid hormone status. These studies required a quantitative method suitable for analysis of small samples. We opted for quantitative real-time RT-PCR (QRTPCR) using SYBR green dye, which intercalates into the DNA backbone, and is measured at the end of each PGR cycle during the exponential phase of the reaction, using a light cycler.

\section{Materials and methods}

\section{Patients studied and sample collection}

Thyroid tissue was collected from five patients with GD and seven patients with multi-nodular goitre (MNG), two of which were toxic. Adipose tissues were collected from three locations: (1) orbital, seven TED patients undergoing decompression and three donors with non-inflammatory eye disease, (2) cervical, eight patients undergoing thyroidectomy for GD or MNG and (3) abdominal, eleven patients undergoing a range of surgical procedures.

Samples were either snap frozen and stored at $-80^{\circ} \mathrm{C}$ prior to RNA extraction or separated into preadipocyte and adipocyte fractions as described below.

All samples were obtained with informed consent and with the approval of the local Bro Taf ethics committee. 
Table 1 Primers and conditions for human QRT-PCR

\begin{tabular}{|c|c|c|c|}
\hline & Primers & $\mathrm{Mg}^{2+} /$ annealing & Amplicon/melting \\
\hline $\begin{array}{l}\text { Gene } \\
\text { APRT } \\
\text { Exons } 3 \text { and } 5\end{array}$ & $\begin{array}{l}\text { f5'gctgcgtgctcatccgaaag } \\
\text { r5'ccttaagcgaggtcagctcc }\end{array}$ & $2.5 \mathrm{mM} / 55^{\circ} \mathrm{C} 2 \mathrm{~s}$ & $247 \mathrm{bp} / 91^{\circ} \mathrm{C}$ \\
\hline $\begin{array}{l}\text { TSHR } \\
\text { Exons } 7 \text { and } 9\end{array}$ & $\begin{array}{l}\text { f5'caatgggacaaagctggatg } \\
\text { r5'tctgattttcttctgattctt }\end{array}$ & $3.5 \mathrm{mM} / 60^{\circ} \mathrm{C} 2 \mathrm{~s}$ & $287 \mathrm{bp} / 85^{\circ} \mathrm{C}$ \\
\hline $\begin{array}{l}\text { PPAR } \gamma \\
\text { Exons } 3 \text { and } 5\end{array}$ & $\begin{array}{l}\text { f5'cagtggggatgtctcataa } \\
\text { r5'cttttggcatactctgtgat }\end{array}$ & $3 \mathrm{mM} / 55^{\circ} \mathrm{C} 2 \mathrm{~s}$ & $390 \mathrm{bp} / 89^{\circ} \mathrm{C}$ \\
\hline
\end{tabular}

$\mathrm{f}$, Forward; $\mathrm{r}$, reverse; $\mathrm{Mg}^{2+}$, final magnesium concentration; annealing, temperature and time for primer annealing; amplicon, size of the PCR product; melting, melting point of the PCR product.

\section{Adipose disaggregation and separation}

Preadipocytes and mature adipocytes were obtained by collagenase digest followed by centrifugation through phthalic acid dionyl ester, as previously described (Crisp et al. 2000). The preadipocytes and mature adipocytes were either used immediately for RNA extraction or resuspended in complete medium and transferred to tissue culture flasks.

\section{Culture conditions and differentiation protocol}

The preadipocytes were grown in complete medium (Dulbecco's modified Eagles' medium/Ham's F12 1:1 media) containing 10\% foetal calf serum (FCS), until confluent, when they were trypsinized, frozen in $10 \%$ dimethyl sulphoxide in FGS and stored in liquid nitrogen. The cells were rapidly thawed, resuspended in complete medium, seeded in 12-well plates and maintained at $37{ }^{\circ} \mathrm{C}$ until $\sim 75 \%$ confluent, when they were transferred to serum-free medium alone or containing differentiation reagents: biotin $33 \mu \mathrm{M}$, panthothenic acid $17 \mu \mathrm{M}$, apotransferrin $10 \mu \mathrm{g} / \mathrm{ml}$, tri-iodothyronine $\left(\mathrm{T}_{3}\right) 0.2 \mathrm{nM}$, cortisol $100 \mathrm{nM}$, insulin $500 \mathrm{nM}$ and $0.25 \mathrm{mM}$ IBMX for the first 3 days. Differentiation continued for a further 8-11 days in differentiation medium without isobutyl methylxanthine (IBMX), when cells were examined for morphological evidence of differentiation and/or oil red $\mathrm{O}$ staining as previously described (Crisp et al. 2000) and RNA was extracted.

\section{RNA extraction, reverse transcription and QRT-PCR}

Solid tissues were weighed prior to pulverization and $900 \mu \mathrm{l}$ solution D (Chomczynski \& Sacchi
1987) added per $100 \mathrm{mg}$ tissue or $5 \times 10^{6}$ cells and the RNA pellets were re-suspended in 20-50 $\mu \mathrm{l}$ water and their absorbance at $260 \mathrm{~nm}$ measured. The resulting total RNA was reverse transcribed using $0 \cdot 1$ units MMLV reverse transcriptase and 40 pmol oligo dT, using a maximum of $1 \mu \mathrm{g}$ RNA or all of the RNA extracted in samples too small for accurate quantification. Real-time PCR was performed, using SYBR green to monitor the kinetics of PCR amplification in a light cycler (Idaho Technology, Salt Lake City, Utah, USA or Roche, Indianapolis, IN, USA), to quantitate transcripts of the housekeeping gene, adenine phosphoribosyl transferase (APRT) and the TSHR. In addition, transcripts of PPAR $\gamma$ were quantified as an indicator of adipogenesis in preadipocytes cultured in either serum-containing medium (SCM) or differentiation medium.

The APRT reactions were performed in the presence of Taqstart antibody (Sigma, St Louis, MO, USA) to produce a 'hot-start'. Results are expressed as transcript copy numbers (TCN) obtained from the crossing points on standard curves established using cloned cDNA for all three genes. The melting curves of the amplicons were compared with that of the standards and the PCR products were retained for gel (and initially sequence) analysis to confirm their identities. Intron/exon spanning primers used, optimized conditions and amplicon sizes are shown in Table 1.

To control for variations in the efficiency of reverse transcription, $1 \mu \mathrm{g}$ RNA extracted from CHO cells stably expressing the human TSHR (Jordan et al. 2001) was always included and the TSHR TGN measured. Results were included only 
Table 2 Primers used in murine QRT-PCR measurements

\begin{tabular}{|c|c|c|c|}
\hline & Primers & $\mathrm{Mg}^{2+} /$ annealing & Amplicon/melting \\
\hline $\begin{array}{l}\text { Gene } \\
\beta \text { actin } \\
\text { Exons } 2 \text { and } 3\end{array}$ & $\begin{array}{l}\text { f5'tgtgatggtgggaatgggtca } \\
\text { r5'tttgatgtcacgcacgatttcc }\end{array}$ & $4 \mathrm{mM} / 62^{\circ} \mathrm{C}$ & $514 \mathrm{bp} / 90^{\circ} \mathrm{C}$ \\
\hline $\begin{array}{l}\text { TSHR } \\
\text { Exons } 4 \text { and } 9\end{array}$ & $\begin{array}{l}\text { f5'aagtttcttggcattttcaata } \\
\text { r5'agtgacgctggtggaag }\end{array}$ & $4.5 \mathrm{mM} / 58^{\circ} \mathrm{C}$ & $333 \mathrm{bp} / 85^{\circ} \mathrm{C}$ \\
\hline
\end{tabular}

from experiments in which the CHO-expressing TSHR gave a value of $1-5 \times 10^{2}$ TSHR TGN and negative controls in the absence of any template were zero.

\section{Induction of hyper- and hypothyroidism in BALBc mice}

Three groups of five 6-week-old male and female BALBc mice were obtained from the breeding colony at the University of Wales College of Medicine (UWCM) and maintained on standard chow and water ad libitum. One group was untreated, a second received $0 \cdot 1 \%(\mathrm{w} / \mathrm{v})$ propylthiouracil (PTU) and the third $12 \mu \mathrm{g} / \mathrm{ml} \mathrm{T}_{3}$, in both cases administered in the drinking water. After 15 days, the animals were killed, blood was obtained for serum and their thyroids, orbital contents, abdominal and epidydimal fat were removed and snap frozen.

All procedures were performed with Home Office approval (project grant number 40/2052).

To confirm that the PTU and $\mathrm{T}_{3}$ treatments had induced hypo- and hyperthyroidism respectively, total thyroxine $\left(\mathrm{T}_{4} ;\right.$ Gamma coat Incstar Corporation, Stillwater, MN, USA) and $\mathrm{T}_{3}$ levels (Biomerica Inc, Newport Beach, CA, USA) were measured by immunoassay according to the manufacturer's instructions.

RNA from all of the snap-frozen tissues was extracted and reverse transcribed, as described above. Real-time PCR was used to quantitate transcripts for the housekeeping gene, $\beta$ actin, and the TSHR using standard curves established with cloned murine cDNA for both genes. The identities of the amplicons were confirmed by melting curve, gel and sequence analysis. Intron/exon spanning primers used, optimized conditions and amplicon sizes are shown in Table 2.

\section{Results}

\section{TSHR TCN is increased in GD thyroid tissue compared with MNG}

In human thyroid tissue, a wide range of TSHR TCN was obtained irrespective of whether results are reported as a ratio with the housekeeping gene, APRT or as an absolute value per $25 \mathrm{ng}$ input RNA. In GD and MNG, the mean TSHR TCN per $25 \mathrm{ng}$ RNA was $9 \cdot 8 \times 10^{3}$ (S.D. $3 \cdot 7 \times 10^{3}$ ) and $1.2 \times 10^{3}$ (S.D. $\left.1.0 \times 10^{3}\right)$ and mean TSHR TCN per 100 APRT was $2 \cdot 7 \times 10^{3}\left(\right.$ S.D. $\left.1 \cdot 1 \times 10^{3}\right)$ and $5 \cdot 7 \times 10^{2}\left(\right.$ S.D. $\left.1.5 \times 10^{2}\right)$ respectively. Results for the individual samples are shown in Fig. 1.

\section{The majority of adipose samples do not express the TSHR; the exceptions being GD and TED}

None of the whole adipose tissues sampled, from the neck or abdomen of patients without GD or TED $(n=11)$, expressed TSHR transcripts, despite APRT TCN being in the range of 100-5000/25 ng input RNA, indicating intact RNA and adequate reverse transcription. In contrast, receptor expression in adipose samples from two out of two TED orbital and three out of three GD neck fats approached the levels found in the thyroid ( 100 TSHR TGN/100 APRT) and, in a single normal orbital fat tested, it was at the limit of detection (<10 TSHR/100 APRT). Results for the individual samples are shown in Fig. 2.

\section{A similar pattern emerges when testing preadipocytes and mature adipocytes}

Five samples of orbital (four TED and one normal) and four samples of abdominal fat were fractionated into preadipocytes and adipocytes 


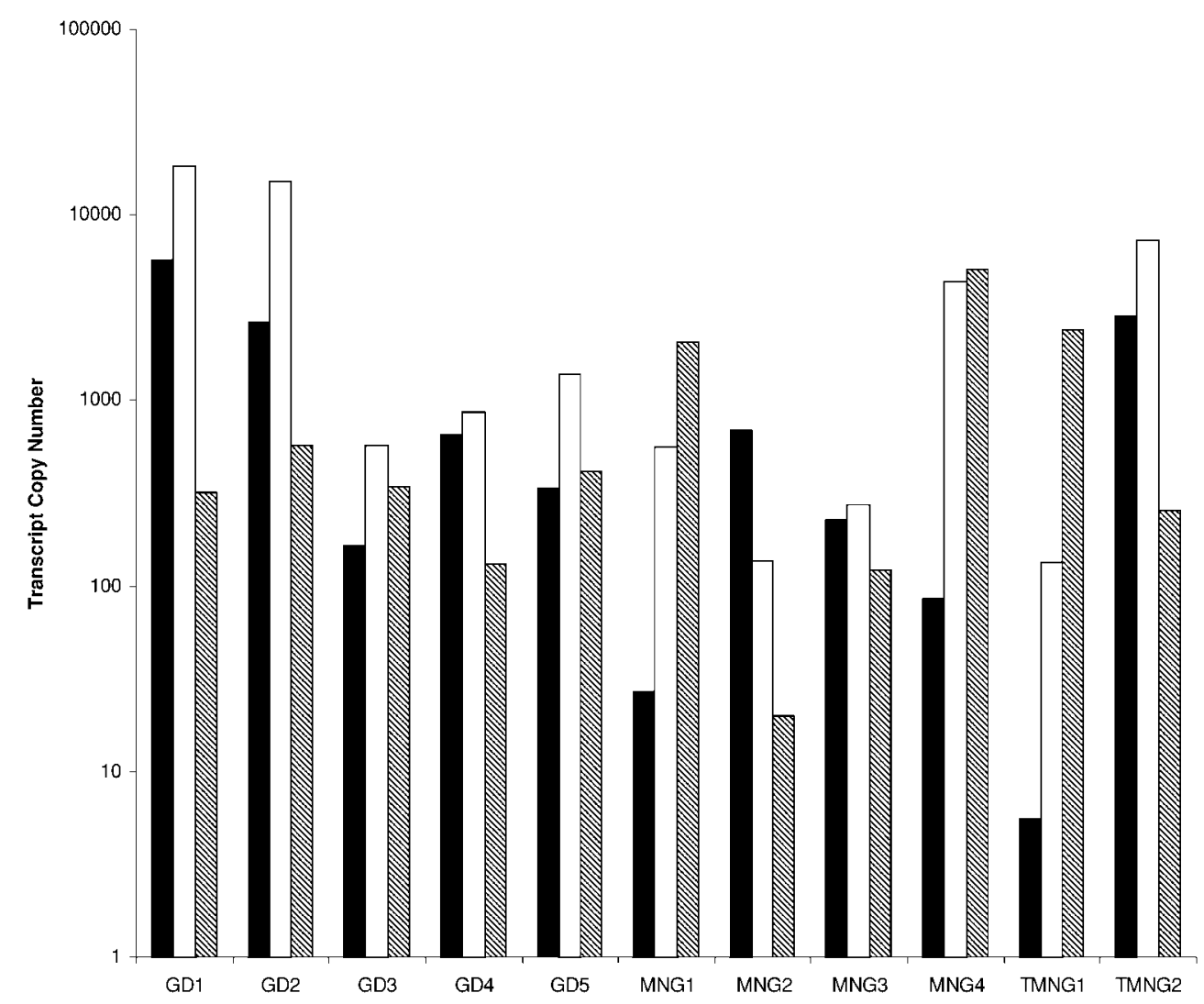

Figure 1 QRT-PCR measurement, reported as TCN on the y axis, of TSHR transcripts in solid thyroid tissues from patients with GD1-5, MNG1-4 and toxic multi-nodular goitre (TMNG1-2). TSHR transcripts per 100 transcripts of APRT (solid bars), TSHR transcripts per $25 \mathrm{ng}$ input RNA (open bars) and APRT transcripts per $25 \mathrm{ng}$ input RNA (shaded bars). All results are the mean of duplicates which vary by $<20 \%$.

and analysed for TSHR TGN directly from the gradient, i.e. with no period in culture. All of the preadipocytes were negative with the exception of the single TED orbital tested, which expressed 10 TSHR TGN per 100 APRT. The situation in the mature adipocytes was more complex with one TED orbital and one abdominal sample at the limit of detection $(<10$ TSHR/100 APRT), two TED orbital samples positive (>10 TSHR/100 APRT) and two abdominal samples negative. Results for the individual samples are shown in Fig. 3.

\section{Short-term culture in FCS or hormone-induced differentiation increases TSHR TCN in preadipocytes}

Three samples of orbital (two TED and one normal) and five samples of abdominal fat were analysed for TSHR TCN following 5 days culture in SCM and/or up to 14 days in differentiation medium. A further two abdominal fat samples were analysed for PPAR $\gamma$ TGN in SGM and differentiation medium. In four of the seven preadipocyte samples cultured in SCM, TSHR transcripts were positive or at the limit of detection irrespective of whether they were derived from patients with GD/TED or not. All differentiating samples expressed >10 TSHR TGN/100 APRT. Results for the individual samples are shown in Fig. 4.

Preadipocytes in SCM have none of the characteristic signs of adipogenesis whereas those in the differentiation protocol are rounded and have lipid droplets, which are oil red $\mathrm{O}$ positive, as shown in Fig. 4. Furthermore, PPAR $\gamma$ transcripts in preadipocytes maintained in SCM are below the limit of detection. In contrast, in the differentiating preadipocytes, levels of this transcription factor, whose expression coincides with that of $\mathrm{C} / \mathrm{EBP} \alpha$ 


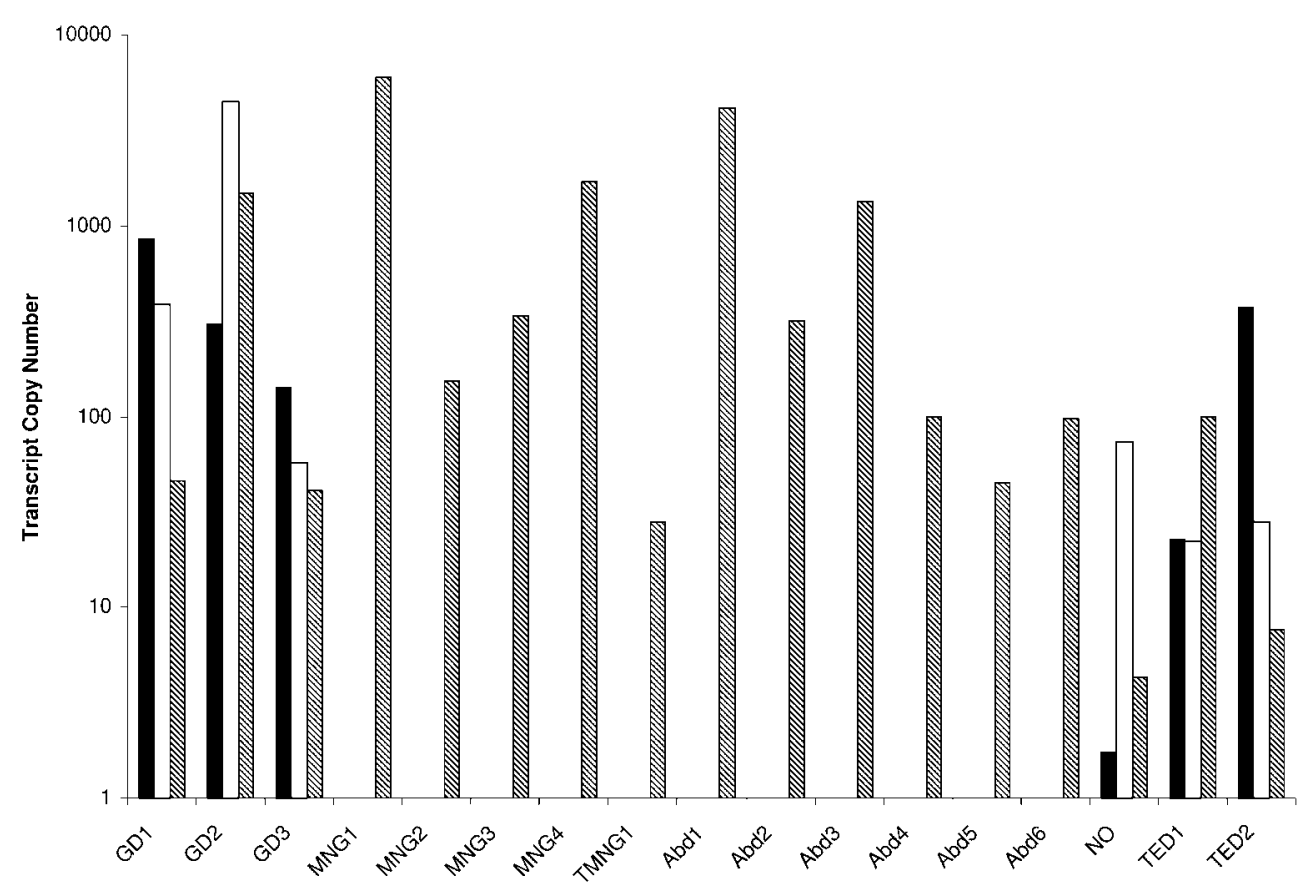

Figure 2 QRT-PCR measurement, reported as TCN on the y axis, of TSHR transcripts in solid adipose tissues from the neck area of patients with GD1-3, MNG1-4, TMNG1, the abdominal fat of patients free of any thyroid dysfunction or TED (Abd1-6) and the orbit of a normal donor (NO) and TED patients (TED1 and 2). TSHR transcripts per 100 transcripts of APRT (solid bars), TSHR transcripts per $25 \mathrm{ng}$ input RNA (open bars) and APRT transcripts per $25 \mathrm{ng}$ input RNA (shaded bars). In samples in which only APRT data are presented, no TSHR transcripts were detected. All results are the mean of duplicates which vary by $<20 \%$.

and thus provides a good marker of adipogenesis (Rosen \& Spiegelman 2000), are increased as summarized in Fig. 5.

In summary, a total of nine adipose samples have been analysed from patients with GD and/or TED ex vivo, either as whole fat samples, preadipocytes or mature adipocytes without a period in culture. Eight of these were positive for TSHR expression, i.e. the TSHR TGN per 100 APRT was $>10$, the remaining sample was at the limit of detection. Conversely, of fifteen fat samples from patients not suffering from GD or TED analysed ex vivo, thirteen were negative for TSHR transcripts and two were at the limit of detection.

At the time of the analysis, all of the patients, even those with GD and/or TED would have been rendered euthyroid as a prerequisite for surgery. To investigate the influence of thyroid hormone status on adipose TSHR expression, we have used a murine model.

\section{Thyroid hormone status does not influence TSHR TCN in murine adipose tissues}

In euthyroid BALBc mice, TSHR TGN in the thyroids ranged from 1 to $3 \times 10^{3} / 25 \mathrm{ng}$ input RNA or 200 to 5000 TSHR/100 $\beta$ actin transcripts and is comparable with the values obtained from diseased (GD or MNG) human thyroid tissues.

We have measured TSHR TCN in the orbital contents, pooled visceral and epididymal adipose depots. All samples were at the limit of detection, i.e. below the $10^{1}$ standard using QRT-PCR, although an amplicon could be detected when the products from 25 PCR cycles were visualized on an ethidium bromide-stained agarose gel, as shown in Fig. 6.

To ensure that the treatment with PTU and $\mathrm{T}_{3}$ had induced hypo- and hyperthyroidism respectively, the total $\mathrm{T}_{4}$ and $\mathrm{T}_{3}$ levels were measured in 


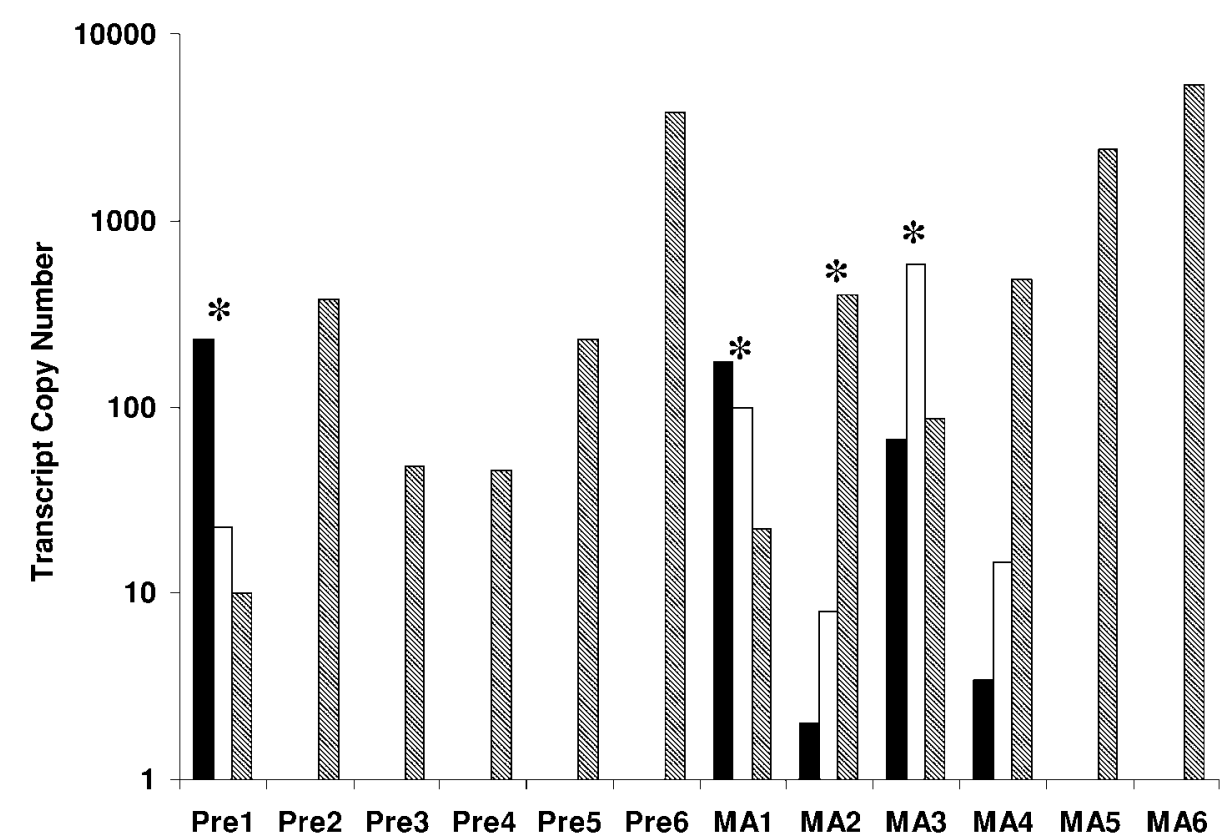

Figure 3 QRT-PCR measurement, reported as TCN on the y axis, of TSHR transcripts in fractionated preadipocytes (Pre1-6) and mature adipocytes (MA1-6) ex vivo, i.e. without a period in culture. Samples with an asterisk are from TED orbital fat and the remaining samples are from normal abdominal or orbital fat. TSHR transcripts per 100 transcripts of APRT (solid bars), TSHR transcripts per $25 \mathrm{ng}$ input RNA (open bars) and APRT transcripts per 25 ng input RNA (shaded bars). In samples in which only APRT data are presented, no TSHR transcripts were detected. All results are the mean of duplicates which vary by $<20 \%$.

the mice. In euthyroid mice, mean total $\mathrm{T}_{4}$ was $4 \cdot 5$ (S.D. $0 \cdot 3)$ and in PTU-treated mice it was $2 \cdot 4$ (s.D. $0 \cdot 35) \mu \mathrm{g} / \mathrm{dl}$. In euthyroid mice, mean total $\mathrm{T}_{3}$ was $1 \cdot 1$ (S.D. $0 \cdot 01$ ) and in $\mathrm{T}_{3}$-treated mice it was $6 \cdot 3$ (S.D. $0 \cdot 7) \mathrm{ng} / \mathrm{ml}$.

When the orbital contents, visceral and epididymal fat pads from the PTU- and $\mathrm{T}_{3}$-treated BALBc mice were analysed by QRT-PGR, the values obtained were at the limit of detection, as in the untreated euthyroid animals, indicating no major influence of thyroid hormone status on adipose TSHR transcript levels. The entire experiment was repeated with similar results.

\section{Discussion}

The present work has confirmed and extended our previous studies and indicates that the TSHR is expressed ex vivo, not only in TED orbital adipose tissues but also in other fat depots from patients with GD. This suggests that the adipose changes present in the orbit, which result in TSHR expression, may be systemic rather than localized and supports the concept that patients with TED (and/or PM) have a severe form of GD. What are those changes likely to be? Previously we have reported oil red $\mathrm{O}$ staining in samples of TED orbital preadipocytes following short-term culture but not in these cells when isolated from patients free of GD and TED (Crisp et al. 2000). Preadipocytes, from any patient and fat depot, which can be induced to differentiate in vitro, express TSHR detectable by immunocytochemistry and have oil red O-positive cells. In the current work, we have found TSHR transcripts only in freshly isolated preadipocytes from TED orbits and in all samples undergoing hormone-induced differentiation. These results indicate that TSHR expression is maximal during adipogenesis and that this process must be ongoing in vivo in any fat sample in which TSHR transcripts can be detected ex vivo, i.e. without in vitro culture. 

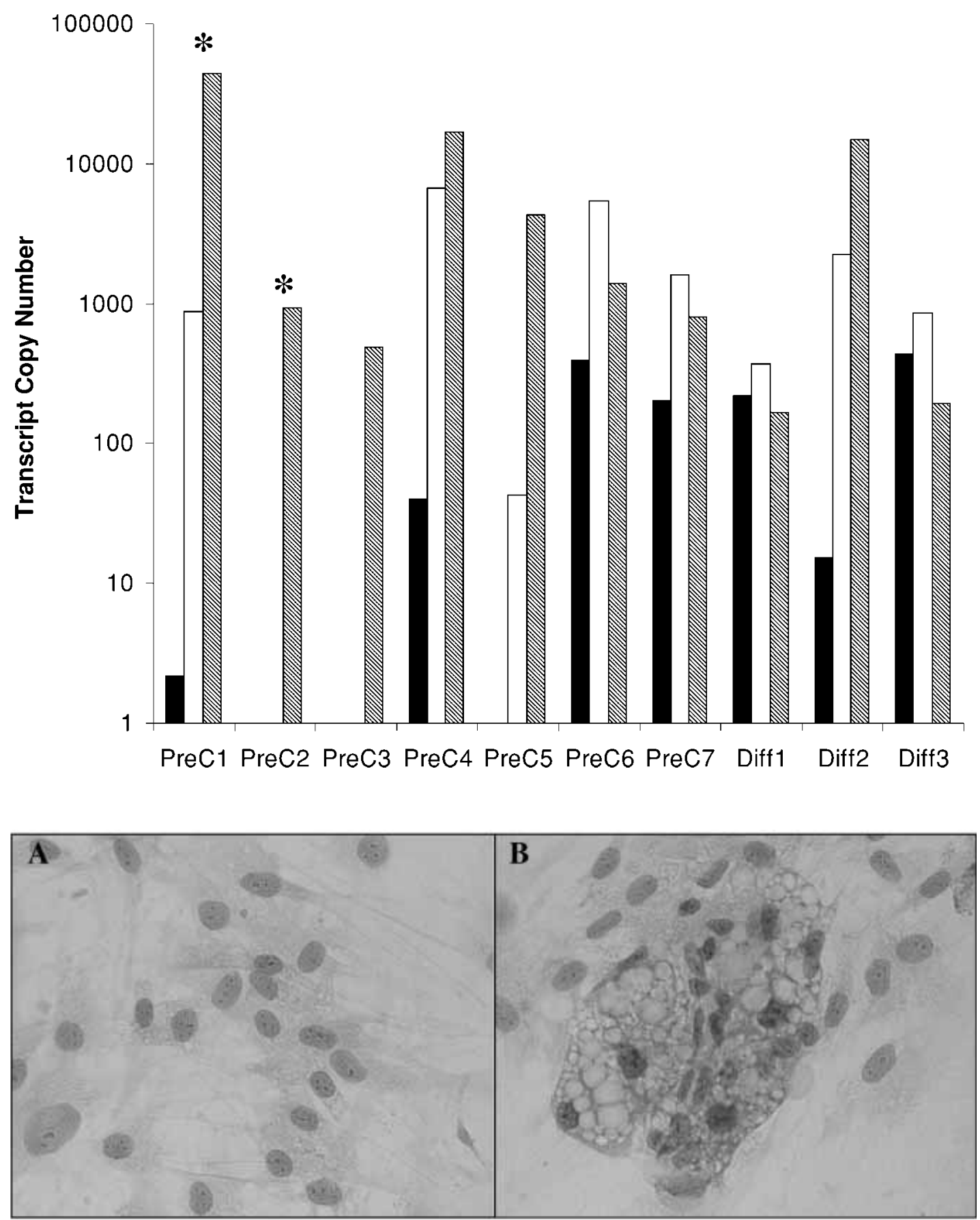

Figure 4 QRT-PCR measurement, reported as TCN on the y axis, of TSHR in fractionated preadipocytes cultured in SCM (PreC1-7) for up to 5 days or following the 14-day differentiation protocol (Diff1-3). Samples with an asterisk are from TED orbital fat and the remaining samples are from normal abdominal or orbital fat. TSHR transcripts per 100 transcripts of APRT (solid bars), TSHR transcripts per $25 \mathrm{ng}$ input RNA (open bars) and APRT transcripts per $25 \mathrm{ng}$ input RNA (shaded bars). In samples in which only APRT data are presented, no TSHR transcripts were detected. The micrographs demonstrate that the preadipocytes in SCM (A) have none of the signs of adipogenesis whilst those in differentiation medium are rounded and have lipid-containing vacuoles (B) which are oil red O positive. All results are the mean of duplicates which vary by $<20 \%$. 


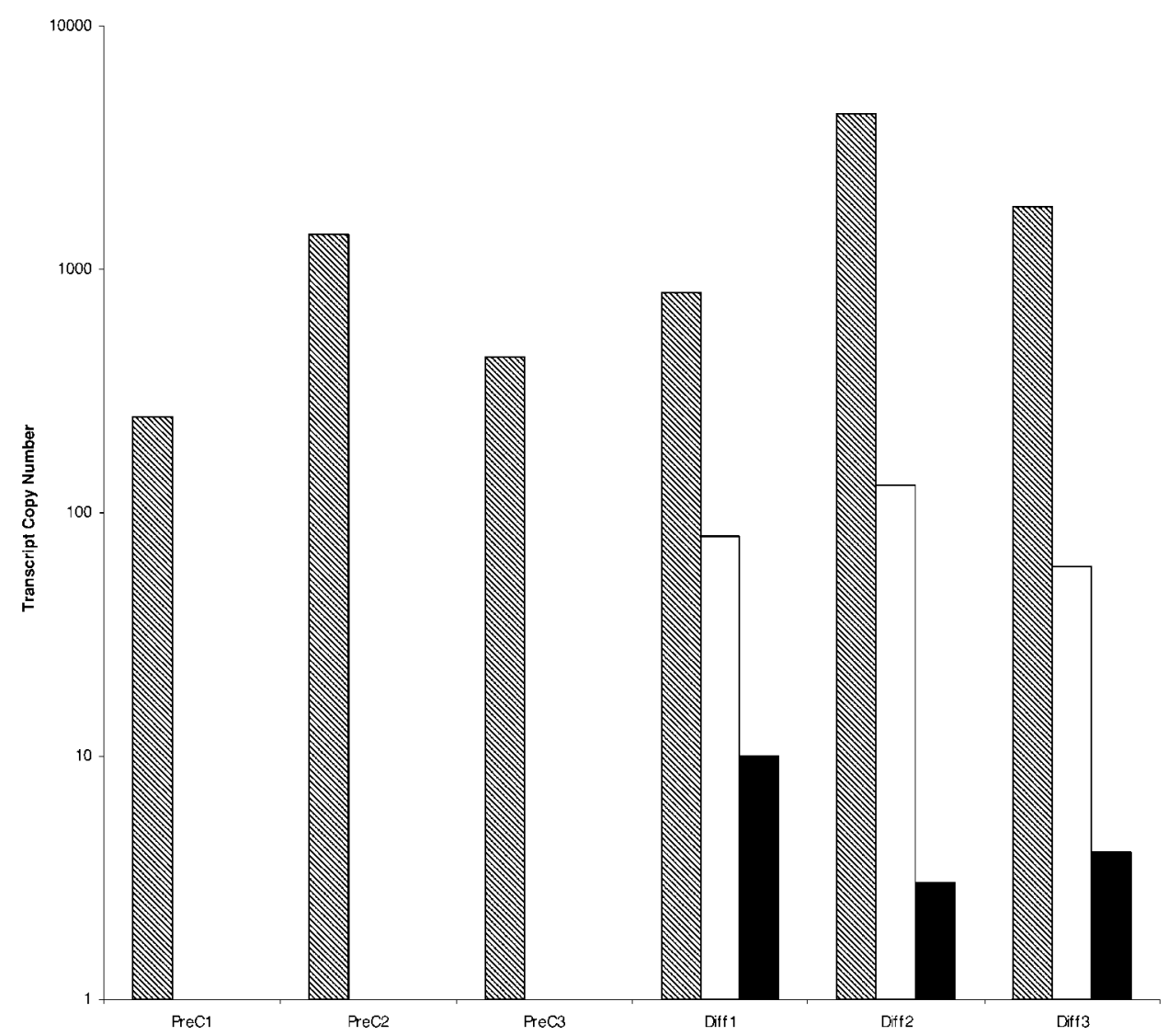

Figure 5 QRT-PCR measurement, reported as TCN on the y axis, of PPAR $\gamma$ in fractionated preadipocytes cultured in SCM (PreC1-3) for up to 5 days or following the 14-day differentiation protocol (Diff1-3). Samples are from normal abdominal fat. APRT transcripts per $25 \mathrm{ng}$ input RNA (shaded bars), PPAR $\gamma$ transcripts per $25 \mathrm{ng}$ input RNA (open bars) and PPAR $\gamma$ transcripts per 100 transcripts of APRT (solid bars). In samples in which only APRT data are presented, no PPAR $\gamma$ transcripts were detected.

Although most authors would agree that TSHR expression is increased during adipogenesis of rodent and human preadipocytes (Haraguchi et al. 1996a,b, Valyasevi et al. 1999) it is not a universal finding. A recent study suggests that TSHR transcript and protein expression are reduced as differentiation proceeds and are maximal in cultured preadipocytes (Bell et al. 2000). Furthermore these cells responded to TSH with an increase in activity of p70S6 kinase, a downstream component of TSH signalling identified in a rat thyroid cell line.

It seems clear that culture conditions can affect gene expression and previously it has been reported that TSHR expression is upregulated by serum in FRTL5 cells and differentiating 3T3 LI (Shimura et al. 1997), with insulin or insulin-like growth
factor-I identified as the active component. The current work demonstrates that TSHR transcripts are present in early passage preadipocytes in short-term culture, when the equivalent population analysed ex vivo were negative. However, this suggests that studies, including our own, showing TSHR immunocytochemistry or functional TSHR, both of which require a period in culture, may be misleading. It is on this basis that functional TSHR expression has been suggested in adipose depots outside the orbit and from individuals having no GD or TED. A limited number of ex vivo Northern analyses (Crisp et al. 1997, Janson et al. 1998) and immunocytochemistry (ICG) studies (Crisp et al. 2000) have shown that such fat tissues can express TSHR at the limit of detection. From our results we would suggest that the TSHR in these samples 

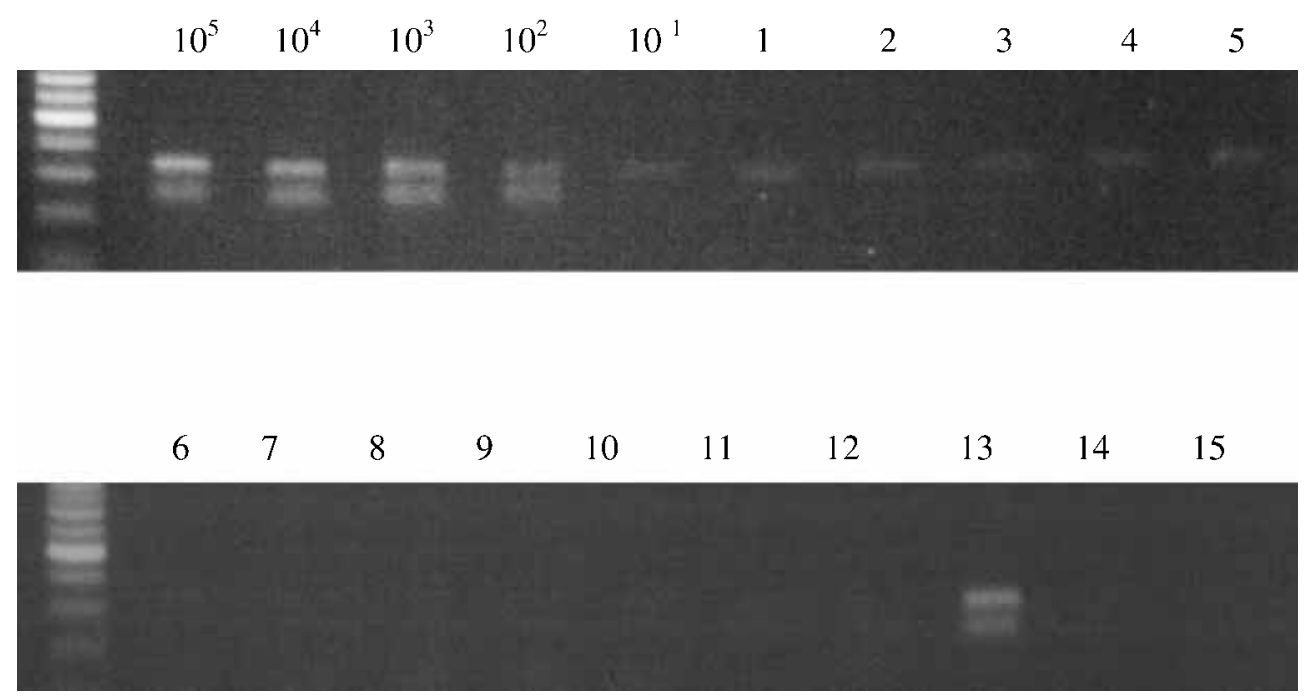

Figure 6 PCR products of the murine TSHR analysed by agarose gel electrophoresis and ethidium bromide staining. Each amplicon was obtained following 25 cycles in a light cycler (Roche). Upper gel: molecular weight standards; cDNA standards used for quantification, $10^{5}$ to $10^{1} ; 1-5$, samples of murine fat which were all at the limit of detection, i.e. below the $10^{1}$ standard when quantified. Lower gel: molecular weight standards; 6-12, samples of murine fat which were all at the limit of detection; 13, murine thyroid which gave a value of $1 \times 10^{3}$ TSHR TCN when quantified; 14, murine kidney negative control and 15, 0 cDNA negative control.

is restricted to mature adipocytes, which are largely refractory to TSH. Conversely, if preadipocytes express the TSHR, they have the capacity to undergo adipogenesis and contribute to pathogenesis via three routes: (1) expanded volume, (2) increased autoantigen expression and (3) elaboration of inflammatory adipocytokines. Whether TSHR ligands can trigger this process in human primary preadipocytes is still not clear although in rat preadipocytes TSH stimulates growth but inhibits differentiation (Haraguchi et al. 1999).

One might reason that our results are based on the measurement of transcripts and this may not equate with protein. In initial experiments to validate the technique we have found that TSHR TCN correlates with functional receptor at the cell surface, at least in $\mathrm{CHO}$ cells transfected with the human TSHR (Evans et al. 1999 data not shown). Furthermore, the results we obtained from preadipocytes in culture showing increased TSHR transcripts (the current study) and TSHR immunoreactivity (Crisp et al. 2000) imply that transcript also correlates with protein in cultured primary cells. The higher levels of TSHR transcript in GD thyroid tissue compared with MNG mirrors our previous demonstration of receptor protein in these glands using ICC (Sequeira et al. 2002).

The results we obtained in the murine adipose tissues are surprising considering the numerous reports of TSHR transcripts in rodent fats and differentiating cells (Roselli-Rehfuss et al. 1992, Endo et al. 1995, Haraguchi et al. 1996a) and of high-affinity TSH binding to rodent epidydimal fat (Iida et al. 1987). The difference may simply reflect the methodology used to detect transcripts since previous studies have analysed the final PCR product to yield a qualitative rather than quantitative result. Even though the BALBc fat samples were at the limit of detection, we were still able to visualize the final PCR product and would have reported these tissues as positive using conventional PCR. Furthermore, we investigated TSHR transcript levels in the adipose tissues of female, euthyroid NOD mice, a strain in which destructive thyroiditis but no orbital pathology can be induced using syngeneic TSHR primed T cells (Many et al. 1999). In common with the BALBc, NOD adipose TSHR transcripts were at the limit of detection (data not shown). We are not aware of any other studies investigating TSHR expression, 
either as transcripts or via TSH binding or signal transduction, in primary murine fat tissues. However, our results are in agreement with previous experiments from one of us showing an absence of TSHR immunoreactivity in BALBc orbital contents, unless a TED-like pathology has been induced in the animal using TSHR primed T cells (Many et al. 1999).

The absence of TSHR expression in cervical fats from TMNG patients and the results obtained in the $\mathrm{T}_{3}$-treated mice suggest that thyroid hormone status does not influence adipogenesis, and thus TSHR expression. However, we are aware that subtle changes may not have been observed in the murine samples when the euthyroid values were at the limit of detection.

In human fat, TSHR expression is an early marker of adipogenesis, since preadipocytes in short-term culture express receptor protein and transcripts but not PPAR $\gamma$ and are oil red $\mathrm{O}$ negative (unless they are derived from TED orbits). If hyperthyroidism per se does not trigger differentiation, it could be caused by inflammatory or autoimmune processes. Recent reports have suggested that interleukin-6 may be implicated (Jyonouchi et al. 2001) but since in vitro manipulation can alter TSHR expression it seems that in vivo experiments will be required to resolve this issue.

In conclusion, we have shown, for the first time, that adipose TSHR expression is associated with the autoimmune or inflammatory process in GD and TED and indicates in vivo adipogenesis in progress but it is not restricted to the orbit or influenced by thyroid hormone status.

\section{Acknowledgements}

We are indebted to Mrs Carol Lane (Department of Ophthalmology, UWCM) and Professor Malcolm Wheeler (Department of Surgery, UWCM) for providing surgical samples and to Dr Mike Christie (Guy's, King's and St Thomas' Medical School, London, UK) for supplying adipose tissue from NOD mice. We thank Professor Gilbert Vassart and Dr Sabine Costagliola (ULB, Brussels, Belgium) for providing cDNAs for the human and mouse thyrotrophin receptors and Brahms Diagnostica GmbH (Hennigsdorf, Germany) for kindly supplying us with ${ }^{125}$ I-TSH. This work was supported by grants from the
Division of Medicine at UWCM and the Wales Office for Research and Development. There are no conflicts of interest that would compromise the impartiality of the authors.

\section{References}

Bahn R, Dutton C, Natt N, Joba W, Spitweg G \& Heufelder A 1998 Thyrotropin receptor expression in Graves' orbital adipose/connective tissues; potential autoantigen in Graves' Ophthalmopathy. Fournal of Clinical Endocrinology and Metabolism 83 998-1002.

Bell A, Gagnon A, Grunder L, Parikh SJ, Smith TJ \& Sorisky A 2000 Functional TSH receptor in human abdominal preadipocytes and orbital fibroblasts. American Fournal of PhysiologyCell Physiology 279 335-340.

Chomczynski P \& Sacchi N 1987 Single step method of RNA isolation by acid guanidium thiocyanate-phenol-chloroform extraction. Analytical Biochemistry 162 156-159.

Costagliola S, Many MC, Denef JF, Pohlenz J, Refetoff S \& Vassart G 2000 Genetic immunization of outbred mice with thyrotropin receptor cDNA provides a model of Graves' disease. Fournal of Clinical Investigation 105 803-811.

Crisp M, Lane C, Halliwell M, Wynford-Thomas D \& Ludgate M 1997 Thyrotropin receptor transcripts in human adipose tissue. Fournal of Clinical Endocrinology and Metabolism 82 2003-2005.

Crisp MS, Starkey, KJ, Lane C, Ham J \& Ludgate M 2000 Adipogenesis in thyroid eye disease. Investigative Ophthalmology and Vision Science 41 3249-3255.

Daumerie C, Ludgate M, Costagliola S \& Many MC 2002 Evidence for thyrotropin receptor immunoreactivity in pretibial connective tissue from patients with thyroid associated dermopathy. European Fournal of Endocrinology 146 35-38.

Davies TF, Teng CS, McLachlan SM, Rees Smith B \& Hall R 1978 Thyrotropin receptors in adipose tissue, retro-orbital tissue and lymphocytes. Molecular and Cellular Endocrinology 9 303-310.

Endo T, Ohta K, Haraguchi K \& Onaya T 1995 Cloning and functional expression of a thyrotropin receptor cDNA from rat fat-cells. Fournal of Biological Chemistry 270 10833-10837.

Evans C, Morgenthaler NG, Lee S, Llewellyn DH, Clifton-Bligh R, John R, Lazarus JH, Chatterjee VKK \& Ludgate M 1999 Development of a luminescent bioassay for thyroid stimulating antibodies. Fournal of Clinical Endocrinology and Metabolism $\mathbf{8 4}$ 374-376.

Feliciello A, Porcellini A, Ciullo L, Bonavolonta G, Avvedimento E \& Fenzi G 1993 Expression of thyrotropin receptor mRNA in healthy and Graves' disease retro-orbital tissue. Lancet 342 337-338.

Hansen C, Fraiture B, Rouhi R, Otto E, Forster G \& Kahaly G 1997 Glycosaminoglycan analysis in patients with Graves' disease. Clinical Science 92 511-517.

Haraguchi K, Shimura H, Lin L, Saito T, Endo T \& Onaya T $1996 a$ Functional expression of thyrotropin receptor in differentiated 3T3-L1 cells: a possible model cell line of extrathyroidal expression of thyrotropin receptor. Biochemical and Biophysical Research Communications 223 193-198.

Haraguchi K, Shimura H, Lin L, Endo T \& Onaya T $1996 b$ Differentiation of rat preadipocytes is accompanied by expression of thyrotropin receptors. Endocrinology 137 3200-3205.

Haraguchi K, Shimura H, Kawaguchi A, Ikeda M, Endo T \& Onaya T 1999 Effects of thyrotropin on the proliferation and differentiation of cultured rat preadipocytes. Thyroid 9 613-619.

Heufelder AE \& Bahn RS 1992 Graves' immunoglobulins and cytokines stimulate expression of intercellular adhesion molecule-1 
(ICAM-1) in cultured Graves orbital fibroblasts. European Fournal of Clinical Investigation 8 529-537.

Heufelder AE, Weetman AP, Ludgate M \& Bahn RS 2000 Pathogenesis of Graves' ophthalmopathy. In Recent Developments in Graves' Ophthalmopathy, pp 15-37. Eds MF Prummel, WM Wiersinga \& MP Mourits. Boston/Dordrecht/London: Kluwer Academic Publishers.

Hufnagel TJ, Hickey WF, Cobbs WH, Jacobiec FA, Iwamoto T \& Eagle RC 1987 Immunohistochemical and ultrastructural studies on the exenterated orbital tissues of a patient with Graves' disease. Ophthalmology 91 1411-1419.

Iida Y, Amir S \& Ingbar S 1987 Stabilization, partial purification and characterisation of thyrotropin receptors in solubilized guinea pig fat cell membranes. Endocrinology 121 1627-1636.

Janson A, Rawet H, Perbeck L \& Marcus C 1998 Presence of thyrotropin receptor in infant adipocytes. Paediatric Research $\mathbf{4 3}$ $555-558$.

Jordan N, Rinderle C, Ashfield J, Morgenthaler N, Lazarus J, Ludgate M \& Evans C 2001 A luminescent bioassay for thyroid blocking antibodies. Clinical Endocrinology 54 355-364.

Jyonouchi SC, Valyasevy RW, Harteneck DA, Dutton CM \& Bahn RS 2001 Interleukin-6 stimulates thyrotropin receptor expression in human orbital pre-adipocyte fibroblasts from patients with Graves' ophthalmopathy. Thyroid 11 929-934.

Ludgate M \& Baker GR 2002 Unlocking the immunological mechanisms of orbital inflammation in thyroid eye disease. Clinical and Experimental Immunology 127 193-198.

Many MC, Costagliola S, Detrait M, Denef JF, Vassart G \& Ludgate M 1999 Development of an animal model of autoimmune thyroid eye disease. Fournal of Immunology 162 4966-4974.

Marcus C, Erhen H, Bolme P \& Armer P 1988 Regulation of lipolysis during the neonatal period importance of thyrotropin. Fournal of Clinical Investigation 82 1793-1797.

Mullin BR, Lee G, Ledley F, Winand R \& Kohn L 1976

Thyrotropin interactions with human fat cell membrane preparations and the finding of a soluble thyrotropin binding component. Biochemical and Biophysical Research Communications 69 $55-62$.
Paschke R \& Ludgate M 1997 The thyrotropin receptor in thyroid disease. New England Journal of Medicine 337 1675-1681.

Perros P \& Kendall-Taylor P 1994 Demonstration of thyrotropin binding sites in orbital connective tissue: possible role in the pathogenesis of thyroid associated ophthalmopathy. Fournal of Endocrinological Investigation 17 163-170.

Rapoport B, Alsabeth R, Aftergood D \& McLachlan SM 2000 Elephantiasic pretibial myxedema: insight into and a hypothesis regarding the pathogenesis of the extrathyroidal manifestations of Graves' disease. Thyroid 10 685-692.

Roselli-Rehfuss L, Robbins LS \& Cone RD 1992 Thyrotropin receptor messenger ribonucleic acid is expressed in most brown and white adipose tissue in the guinea pig. Endocrinology 130 1857-1861.

Rosen ED \& Spiegelman BM 2000 Molecular regulation of adipogenesis. Annual Review of Cell and Developmental Biology 16 $145-171$.

Sequeira MJ, Morgan JM, Fuhrer D, Wheeler MH, Jasani B \& Ludgate M 2002 Demonstration of reduced in vivo surface expression of activating mutant thyrotropin receptors in thyroid sections. European Fournal of Endocrinology 146 163-171.

Shimura H, Harguchi K, Endo T \& Onaya Y 1997 Regulation of thyrotropin receptor gene expression in 3T3-L1 adipose cells is distinct from its regulation in FRTL-5 thyroid cells. Endocrinology $130520-533$.

Sorisky A, Pardasani D, Gagon A \& Smith TS 1996 Evidence for adipocyte differentiation in human orbital fibroblasts in primary culture. Fournal of Clinical Endocrinology and Metabolism $\mathbf{8 1}$ 3428-3431.

Valyasevi R, Erickson D, Harteneck D, Dutton C, Heufelder A, Jyonouchi S \& Bahn R 1999 Differentiation of human orbital preadipocyte fibroblasts induces expression of functional thyrotropin receptor. Fournal of Clinical Endocrinology and Metabolism $842557-2562$.

\section{Received 4 December 2002} Accepted 20 December 2002 